\title{
THE NORADRENALINE REUPTAKE INHIBITOR ATOMOXETINE PHASE- SHIFTS THE CIRCADIAN CLOCK IN MICE
}

\author{
S. M. O'KEEFFE, ${ }^{\text {a }}$ J. THOME ${ }^{\mathrm{b}}$ AND A. N. COOGAN ${ }^{\mathrm{a} *}$ \\ ${ }^{a}$ Department of Psychology, National University of Ireland Maynooth, \\ Co. Kildare, Republic of Ireland \\ ${ }^{b}$ Department of Psychiatry, School of Medicine, University of Rostock, \\ Germany
}

\begin{abstract}
Circadian rhythms are recurring cycles in physiology and behaviour that repeat with periods of near $24 \mathrm{~h}$ and are driven by an endogenous circadian timekeeping system with a master circadian pacemaker located in the suprachiasmatic nucleus (SCN). Atomoxetine is a specific noradrenaline reuptake inhibitor that is used in the clinical management of attention-deficit/hyperactivity disorder (ADHD). In the current study we examined the effects of atomoxetine on circadian rhythms in mice. Atomoxetine (i.p.; $3 \mathrm{mg} / \mathrm{kg}$ ) treatment of mice free-running in constant light (LL) at circadian time (CT) 6 induced large phase delays that were significantly different to saline controls. Treatment of animals with atomoxetine at CT13 or CT18 did not elicit any significant phase shifts. We also examined the effects of atomoxetine treatment of animals free-running in constant darkness (DD). Atomoxetine treatment at CT6 in these animals leads to more modest, but significant, phase advances, whereas treatment at CT18 did not elicit significant phase shifts. The effects of atomoxetine in LL were attenuated by pretreatment with the $\alpha-1$ adrenoreceptor antagonist prazosin and were mimicked by another noradrenaline reuptake inhibitor, reboxetine. Further, atomoxetine treatment at CT6 induced a downregulation of c-Fos and CLOCK in the SCN, but did not alter the expression of PER2 and BMAL1. Atomoxetine during the night phase did not alter any of these factors. Atomoxetine treatment preceding a light pulse at CT15 enhanced the magnitude of the photic-phase shift, whereas it altered photic induction of the immediate early gene products c-Fos and ARC in the SCN. These data indicate that atomoxetine can reset the circadian clock and indicate that part of the therapeutic profile of atomoxetine may be through circadian rhythm modulation. (c) 2011 IBRO. Published by Elsevier Ltd. All rights reserved.
\end{abstract}

Key words: atomoxetine, circadian, suprachiasmatic, reboxetine, c-Fos, clock.

Circadian rhythms are near 24-h recurring cycles in a host of behavioural and physiological parameters that are underpinned by an endogenous circadian timekeeping system (Reppert and Weaver, 2002). In mammals the master pacemaker of this circadian system is located in the suprachiasmatic nucleus (SCN) of the anterior hypothala-

*Corresponding author. Tel: +353(8)-1-7086624; fax: +353(8)-1-7084767. E-mail address: andrew.coogan@nuim.ie (A. N. Coogan).

Abbreviations: ADHD, attention-deficit/hyperactivity disorder; $\mathrm{CT}$, circadian time; DD, constant darkness; IEG, immediate early gene; LL, constant light; NA, noradrenaline; SCN, suprachiasmatic nucleus. mus, which receives afferent input allowing the entrainment of the circadian clock to appropriate sensory and environmental time cues (zeitgebers), the dominant one being light (Dibner et al., 2010). The molecular machinery that allows for stable generation of such circadian rhythms is now known to consist of a panel of clock genes that regulate both their own expression and also those of clockcontrolled genes, with various studies demonstrating that approximately $10 \%$ of the transcriptome of various tissues displays significant circadian rhythmicity (Hogenesch et al., 2003).

The SCN is known to receive input from a number of midbrain and brainstem regions (Moga and Moore, 1997) as well as projecting indirectly to key brainstem areas such as the locus coereleus in order to drive circadian rhythms in arousal (Aston-Jones et al., 2001). Some input pathways have received sustained attention in the research literature (e.g. the serotoninergic input; Morin and Allen, 2006), whereas other systems have received somewhat less attention. The $\mathrm{SCN}$ is known to receive noradrenergic innervation (Cagampang et al., 1994; Jacomy and Bosler, 1995), with noradrenaline (NA) levels displaying rhythms in the rat and hamster SCN (Semba et al., 1984; Cagampang et al., 1994) as well as throughout the rest of the brain (e.g. Manshardt and Wurtman, 1968). The role of NA in regulating SCN function is not clear, although it has been proposed that NA regulates the expression of the key SCN neuropeptides arginine vasopressin and vasoactive intestinal polypeptide (Vacher et al., 2003, 2004). Further, it has been noted that the SCN expresses both $\alpha-1$ and $\alpha-2$ adrenoreceptors (Morien et al., 1999). There have been a limited number of studies examining the effects of adrenergic agents on circadian organization of behaviour and clock gene regulation (Rosenwasser, 1996; Terazono et al., 2003; Wongchitrat et al., 2009) with many issues regarding the adrenergic regulation of the master SCN circadian clock remaining unascertained. One such issue is the extent to which medication used to treat affective and other psychiatric disorders, which target the noradrenergic system, may exert their effects through a circadian modulation. For example, the noradrenaline reuptake inhibitor reboxetine is licensed for use in the treatment of major depression, which itself has long been associated with circadian desynchrony (Wirz-Justice, 2009). Further, another noradrenaline reuptake inhibitor, atomoxetine, is licensed for the treatment of attention deficit/hyperactivity disorder (ADHD), which again has been associated with phase misalignment of the circadian clock (Van Veen et al., 2010). Given that correction of these circadian discrepancies is associated with symptom relief (Coogan and 
Thome, 2011), it is of interest to inquire as to the actions of noradrenergic modulating drugs on circadian rhythms. To this end we have studied the effects of atomoxetine on circadian rhythms in the mouse in order to gain insight into putative mechanisms that may be of importance in human psychopharmacology. As non-photic stimuli that phaseshift the clock also suppress expression of clock genes in the SCN (e.g. Maywood et al., 1999) we have also examined the effect of atomoxetine on the expression of a number of clock gene protein products.

\section{EXPERIMENTAL PROCEDURES}

\section{Animals and housing}

Male C57BL/6 mice (22-25 g) obtained from Harlan Laboratories (Leicestershire, UK) were used throughout this study. Animals were singly housed in polypropylene cages equipped with running wheels $(11 \mathrm{~cm}$ diameter) with food and water available ad libitum and temperature held constant at $21 \pm 1{ }^{\circ} \mathrm{C}$ and humidity at $50 \pm 10 \%$. Cages were then housed in an environmental isolation cabinet to allow for full control of the photic environment. They were illuminated using a fluorescent white light source, with average illuminance of $250 \mathrm{~lx}$ at the level of the cage floor when lights were on. Bedding was changed every 14 days, and never in the period leading up to or after a pharmacological intervention. All experiments were approved by the Research Ethics Committee, National University of Ireland Maynooth and licensed by the Irish Department of Health and Children and conformed to the European Communities Council Directive of 24 November 1986 (86/ $609 / E E C)$. All efforts were made to reduce the number of animals used in the study, as well as any pain and suffering.

\section{Circadian rhythm monitoring}

Wheel running was monitored through microswitches attached to the running wheels communicating with the Chronobiology Kit (Stanford Software Systems, CA, USA) to allow for production of actograms of wheel-running behaviour. Before any pharmacological intervention animals were allowed to free-run for 2 weeks to allow for analysis of stable baselines of circadian factors. Phase shifts were rated by two to three independent observers blind to the treatments by means of the line-of-best-fit method through activity onsets for 7 days before and after any intervention. Phase shifts were calculated as the difference in the regression lines before and after the intervention, calculated on the day following the intervention. Period length and rhythm strength were obtained from Poisson Periodograms in the Chronobiology kit.

\section{Drugs}

Atomoxetine $\mathrm{HCl}$ was obtained from Tocris Bioscience (Bristol, UK), dissolved in $0.9 \%$ sterile saline and administered i.p. at a dose of $3 \mathrm{mg} / \mathrm{kg}$, a dose which has been previously shown to elicit neurochemical effects in rodent brain (e.g. Bymaster et al., 2002). Prazosin and reboxetine were also obtained from Tocris Bioscience and administered at doses of $4 \mathrm{mg} / \mathrm{kg}$ i.p. and $20 \mathrm{mg} / \mathrm{kg}$ i.p., doses previously determined to be effective in similar approaches (Cryan et al., 2004).

\section{Effects of atomoxetine and reboxetine on free running circadian rhythms}

In these experiments, animals were maintained in cages with running wheels under a 12:12 light:dark cycle for 2 weeks before being released into constant conditions (either constant light (LL) or constant darkness (DD)). Both photic backgrounds were used, as previous research has indicated that LL enhances phaseshifting in response to some stimuli (Knoch et al., 2004). Animals were allowed to free run for 2 weeks before the first drug treatment. Animals ( $n=8$ for LL and $n=8$ for DD) received an injection of atomoxetine $(3 \mathrm{mg} / \mathrm{kg})$ and an injection of saline at circadian time (CT) 6 , each treatment separated by 14 days before being crossed over to the other treatment, such that each animal received both atomoxetine and vehicle. Further to this, each animal then received atomoxetine or saline at CT18.

To further test the phase-specificity of atomoxetine's actions a separate group of mice $(n=8)$ were free-run in LL and in a counterbalanced cross-over design received atomoxetine/saline at CT13 followed by the complementary treatment 2 weeks later, followed by a further 14-day free running to allow for accurate rating of the stable phase shift. Timepoints were selected on the basis of previous studies of phase-dependence of non-photic and pharmacological manipulations that produce phase shifts, which typically indicated efficacy when applied in the subjective day but not the subjective night.

To test whether another noradrenaline reuptake inhibitor, reboxetine, would have a similar effect as to atomoxetine, mice $(n=8)$ were free-run in LL for 2 weeks before receiving either reboxetine $(20 \mathrm{mg} / \mathrm{kg}$, i.p.) or saline, before receiving the complementary treatment 14 days later, followed by a further 14 days of free running. To test whether the effects of atomoxetine were modulated by an adrenergic receptor antagonist, prazosin, a group of mice $(n=8)$ were free-run in LL for 14 days before receiving treatment with atomoxetine at CT6 coupled with either prazosin treatment $(4 \mathrm{mg} / \mathrm{kg}$, i.p.; $n=4)$ or saline treatment $(n=4)$ $30 \mathrm{~min}$ before the atomoxetine treatment (so at CT5.5). After a further 14 days animals again received atomoxetine at CT6 preceded by either saline or prazosin in a cross-over design, so that each animal received atomoxetine plus prazosin and atomoxetine plus saline.

\section{Effects of atomoxetine in modulating photic phase shifts}

In this experiment we examined whether atomoxetine pretreatment would alter light-induced phase shifts of the circadian rhythm. Mice $(n=12)$ were free-run in DD for 2 weeks, before receiving a $30 \mathrm{~min}$ light pulse $(150 \mathrm{Ix})$ at CT15-CT15.5, the circadian phase at which a maximal phase delay is elicited in mice (e.g. Pendergast et al., 2010). Thirty min before the light pulse animals received an i.p. injection of either atomoxetine $(3 \mathrm{mg} / \mathrm{kg})$ or saline. Animals were then allowed to free run for another 14 days before receiving another light pulse at CT15 crossed over to the complementary atomoxetine/saline treatment, so that each animal received two light pulses at CT15, one preceded with atomoxetine and one with saline.

\section{Effects of atomoxetine on clock gene production expression in the SCN}

At the end of each behavioural experiment animals received a final treatment and then were killed by cervical dislocation and their brains removed and fixed for immunohistochemical processing. Animals received atomoxetine or saline at CT6 in LL, atomoxetine or saline at CT13 in LL, atomoxetine or saline at CT6 in $\mathrm{DD}$, reboxetine or saline in LL at CT6 and atomoxetine at CT6 preceded by saline at CT5.5 or atomoxetine at CT6 preceded by prazosin at CT5.5 ( $n=4$ for each treatment group). Animals were sampled and brains removed $2 \mathrm{~h}$ following the final treatment. For light pulse experiments animals received saline plus a 30-min light pulse at CT15 $(n=4)$ or atomoxetine at CT14.5 followed by a 30-min light pulse at CT15 $(n=4)$ before being sampled $1 \mathrm{~h}$ after the onset of the light pulse. Brains were immersion fixed as previously described (Beynon et al., 2009) before being cryoprotected in $30 \%$ sucrose. Brains were then sectioned coronally into 
$30 \mu \mathrm{m}$ sections on a freezing stage sledge microtome (Leica, UK). Sections containing the SCN were then processed for immunohistochemistry using a standard avidin-biotin complex (ABC)/nickel-DAB protocol (e.g. Beynon et al., 2009). Briefly, following peroxidase inactivation and blocking with serum, sections were incubated with primary antibody in $1 \%$ normal goat/rabbit serum (as appropriate for the primary antibodies used) overnight before being developed with biotinylated secondary antibodies (1:400) and $\mathrm{ABC}(0.4 \%$; Vector Laboratories, Peterborough, Cambridgeshire, UK). Reaction product was visualized using nickel$\mathrm{DAB}$. All sections were reacted under the same conditions for the same amount of time across treatment groups for each antibody to ensure equivalence of staining and minimization of inter-run variability. Primary antibodies used in this study were c-Fos (rabbit polyclonal, sc-52, diluted 1:2000), CLOCK (goat polyclonal, sc6928, diluted 1:500), BMAL-1 (rabbit polyclonal, sc-48790, diluted 1:500) and PER2 (rabbit polyclonal, sc-25363, diluted 1:500); all from Santa Cruz Biotechnology (Heidleberg, Germany). The use and specificity of these antibodies have been previously described (e.g. Wyse and Coogan, 2010; Borgs et al., 2009), but to confirm this, where available, the immunizing peptides were used in adsorption controls and ablated immunostaining. For photic stimulation experiments similar protocols were used with the same c-Fos antibody as above and a rabbit polyclonal antibody raised against the immediate early gene product ARC (Santa Cruz sc-15325). Both c-Fos and ARC are immediate early genes whose expression in the SCN is upregulated by photic stimulation (Kornhauser et al., 1990; Nishimura et al., 2003).

After being dehydrated, delipified and cover-slipped, sections were analysed on an Olympus BX51 microscope equipped with a DP-12 digital camera. Sections across the rostro-caudal extent of the SCN were examined. There were at least six SCN sections per animal examined. Cell counting was by an observer blinded to the treatment. Only densely, unambiguously stained cells were counted as being immunopositive. For graphical representation of cell counts across different antigens, cell counts for each salineand drug-treated animal were normalized to the overall average counts for the appropriate control group (e.g. for c-Fos counts in the SCN after saline or atomoxetine treatment in LL at CT6 counts for each animal were normalized to the average c-Fos count for the saline group in LL treated at CT6).

\section{Statistical analysis}

Data were analysed using a mix of within-groups and betweengroups $t$-tests and factorial ANOVAs, with Bonferroni corrections made for multiple comparisons where required. Test type used is quoted throughout the results section. All data are presented as mean \pm standard error of the mean. All statistical analysis was carried out with PASW statistics 18 (IBM) with significance set at $P<0.05$.

\section{RESULTS}

\section{Atomoxetine phase shifts circadian locomotor rhythms}

We examined the effects of atomoxetine administration at different times of the circadian cycle (CT6, CT13, CT18) and against different photic backgrounds (LL vs. DD) on free-running circadian locomotor rhythms. Two-way factorial ANOVA with time of treatment and photic background as the independent variables reveals main effects of time of treatment $(F(2,32)=60.1, P<0.001)$ and photic background $(F(1,32)=63, P<0.001)$, as well as a significant interaction between time of treatment and photic background $(F(1,32)=60, P<0.001)$ on the phase shifts elicited by atomoxetine. Further examination of these effects revealed that atomoxetine treatment at CT6 in LL elicited a large phase delay of the behavioural circadian rhythm $(-3.15 \pm 0.27 \mathrm{~h}$ for atomoxetine vs. $-0.61 \pm 0.18 \mathrm{~h}$ for saline; $P<0.001$ paired $t$-test; Fig. $1 \mathrm{~A}, \mathrm{~B})$. When the effects of atomoxetine on rhythms in DD were examined it was found that treatment at CT6 elicited a moderate but significant phase advance of the rhythm $(0.96 \pm 0.22 \mathrm{~h}$ for atomoxetine vs. $0.09 \pm 0.18$ for saline, $P<0.001$ by paired $t$-test; Fig. 1C, D). There were no significant phase shifts induced when atomoxetine was administered in LL at CT13 $(0.64 \pm 0.21 \mathrm{~h}$ for atomoxetine vs. $0.21 \pm 0.17 \mathrm{~h}$ for saline; Fig. 3) or at CT18 $(0.41 \pm 0.11 \mathrm{~h}$ for atomoxetine vs. $0.57 \pm 0.19 \mathrm{~h}$ for saline; Fig. 1E). Treatment with atomoxetine at CT18 in DD also did not elicit a significant phase shift $(0.23 \pm 0.1 \mathrm{~h}$ for atomoxetine vs. $0.12 \pm 0.13 \mathrm{~h}$ for saline; Fig. 1E).

There were no significant changes in the period or the strength of the free-running rhythm following atomoxetine treatment in either LL or DD (data not shown), nor was there any marked acute response directly following atomoxetine treatment (e.g. no unexpected periods of locomotor behaviour).

\section{Effects of atomoxetine on clock gene and immediate early gene expression in the SCN}

We examined the effect of atomoxetine treatment on cFos, CLOCK, PER2 and BMAL1 expression in the SCN at CT6 in both LL and DD. Two-way ANOVA with treatment and photic background as the fixed factors reveal that there was a main effect of treatment $(F(1,15)=22.3$, $P<0.001)$ but not of photic background nor was there a treatment $\times$ photic background interaction (both $P>0.05$ ). For CLOCK expression there were main effects for treatment $(F(1,15)=6.3, \quad P<0.05)$ and photic background $(F(1,15)=27.8, P<0.001)$ as well as significant interaction between treatment and photic background $(F(1,15)=28.1$, $P<0.001)$. There were no main effects of treatment or photic background on BMAL1 or PER2 expression, nor were there significant interactions between treatment and photic background for both of these antigens (all $P>0.05$ ).

Further pairwise analysis revealed that treatment with atomoxetine at CT6 in LL elicited a decrease in the expression of C-Fos and CLOCK expression in the SCN $(P<0.01$ compared with saline controls by independent $t$-test), but not of BMAL1 or PER2 expression (Fig. 2). Atomoxetine treatment in DD at CT6 induced a significant decrease in c-Fos expression in the SCN $(P<0.05$ compared with saline controls by independent $t$-test), but not of CLOCK, BMAL1 or PER2 (Fig. 3A). Treatment with atomoxetine in LL at CT13 did not elicit any significant changes in expression of c-Fos, CLOCK, BMAL-1 or PER2 (Fig. 3B).

\section{Effects of reboxetine on circadian rhythms and clock gene product expression}

In order to examine whether other specific noradrenaline reuptake inhibitors may exert similar effects as atomoxetine, animals in LL were treated with reboxetine or saline 

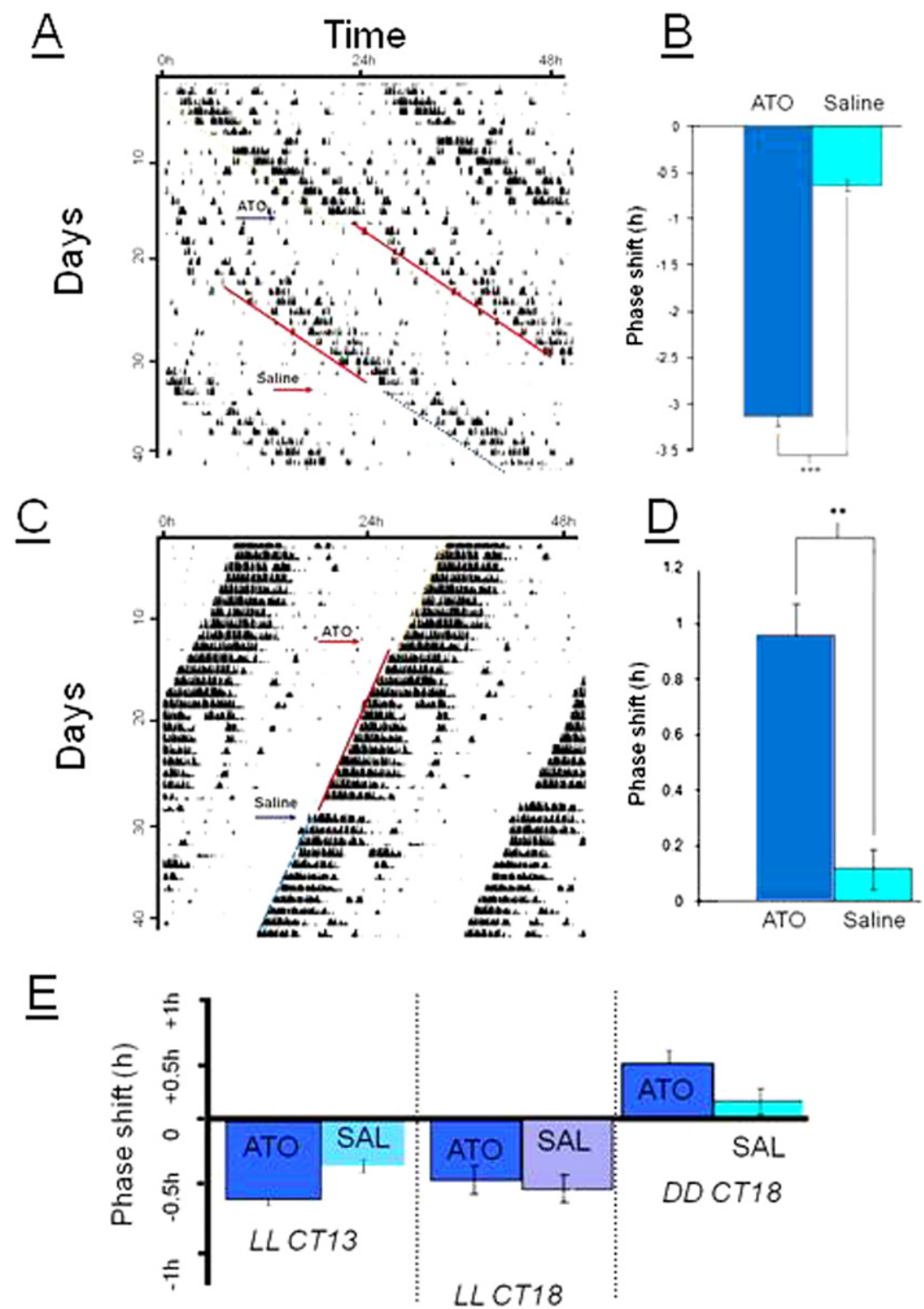

Fig. 1. Atomoxetine induces phase shifts of locomotor circadian rhythms. (A) Sample double plotted actogram of a mouse free-running in LL treated with atomoxetine (ATO) and saline (treatments indicated by the arrows) at CT6. Note the large delay induced by atomoxetine treatment. Diagonal lines indicate lines of best fit through the activity onsets, where activity onset is defined as CT12. (B) Mean phase shifts produced by atomoxetine or saline at CT6 in LL (*** denotes $P<0.001 ; n=8$ ). (C) Atomoxetine induces modest phase advances in DD. Sample double plotted actogram showing that atomoxetine (ATO) treatment at CT in DD produces a phase advance of approximately 60 min. (D) Mean phase shifts produced by atomoxetine or saline at CT6 in DD ( ${ }^{* *}$ denotes $\left.P<0.01 ; n=8\right)$. (E) Atomoxetine treatment in the night phase does not induce significant phase shifts. Mean phase shifts produced by atomoxetine or saline in LL at CT13 or CT18 and at CT18 in DD. There are no significant differences between atomoxetine and saline treatments. For interpretation of the references to colour in this figure legend, the reader is referred to the Web version of this article.

(20 mg/kg, i.p.) at CT6. This was found to result in a significant phase delay following reboxetine treatment when compared with saline $(-2.08 \pm 0.27 \mathrm{~h}$ vs. $-0.24 \pm$ $0.18 \mathrm{~h}$ for saline control; $P<0.01$ by paired $t$-test; Fig. $4 \mathrm{~A}$, $B)$. Reboxetine did not elicit any significant alterations in the free-running period nor in the amplitude of the circadian rhythm. When the SCN of animals treated with reboxetine at CT6 in LL were examined it was shown that, similar to atomoxetine, treatment resulted in a suppression of c-Fos and CLOCK $(P<0.05$ and $P<0.01$ compared with saline and controls respectively by independent $t$-test), but not of BMAL1 and PER2 (Fig. 4C).

\section{Effects of pretreatment with prazosin on atomoxetine-induced effects}

Animals were treated with atomoxetine in LL at CT6 after being treated with either prazosin or saline. Pretreatment with prazosin significantly attenuated the atomoxetine-induced phase delay $(-0.45 \pm 0.17 \mathrm{~h}$ for prazosin and atomoxetine treatments compared to $-2.26 \pm 0.18 \mathrm{~h}$ for saline and atomoxetine; $P<0.001$ by paired $t$-test; Fig. 5A, B). When the effects of prazosin pretreatment on atomoxetine-induced effects in the SCN were examined it was found that $\mathrm{SCN}$ from animals that 


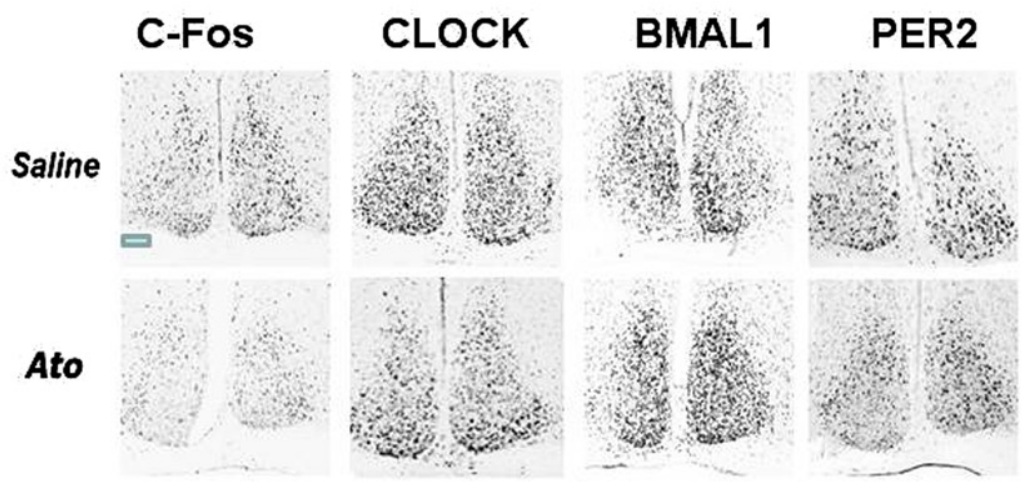

B

C-Fos

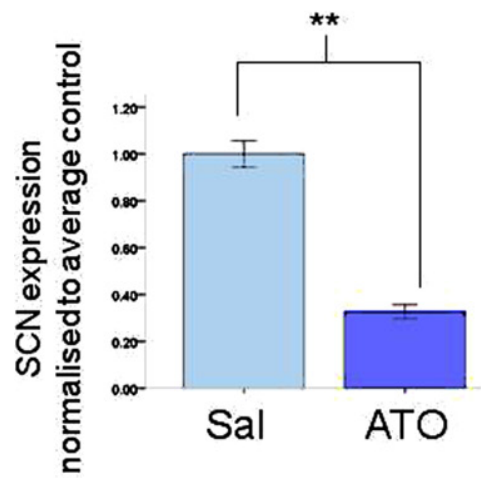

CLOCK

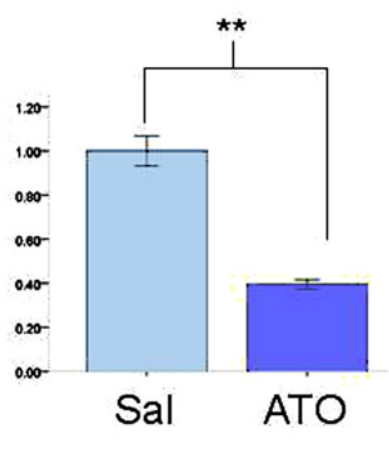

BMAL1

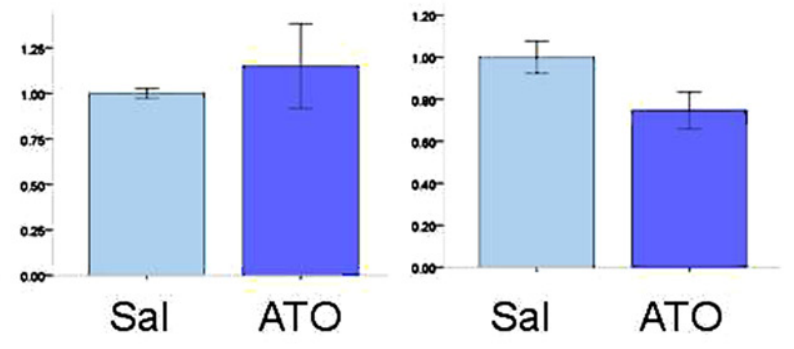

Fig. 2. Atomoxetine suppresses c-Fos and CLOCK expression in the SCN. (A) Sample photomicrographs of c-Fos, CLOCK, BMAL1 and PER2 in the SCN $2 \mathrm{~h}$ following a treatment with either atomoxetine or saline at CT6 in LL. Scale bar $=100 \mu \mathrm{m}$. (B) Effects of atomoxetine on c-Fos, CLOCK, BMAL1 and PER2 expression in the SCN compared with saline treatment group. ${ }^{* *}$ Denotes $P<0.01$. For interpretation of the references to colour in this figure legend, the reader is referred to the Web version of this article.

had been treated with saline and atomoxetine expressed significantly less c-Fos and CLOCK than those sections from animals pretreated with prazosin before atomoxetine administration $(P<0.05$ for prazosin + atomoxtine vs. saline+atomoxetine by paired $t$-test; Fig. $5 C$ ).

\section{Effects of atomoxetine on light-induced phase shifts}

Pretreatment with atomoxetine before a light pulse at CT15 in animals in DD led to a significant enhancement of the photic phase shift compared with that produced by saline treatment and photic stimulation $(-2.2 \pm 0.13 \mathrm{~h}$ for atomoxetine plus light pulse vs. $-1.89 \pm 0.15 \mathrm{~h}$ for saline plus light pulse; $P<0.01$ by between groups $t$-test; Fig. $6 \mathrm{~A}, \mathrm{~B})$. Further, when the effects of atomoxetine on light-induced c-Fos and ARC were examined in the SCN to test whether photic responsiveness was altered at the molecular level, it was found that atomoxetine-treated animals expressed significantly less SCN c-Fos and ARC than saline-treated controls following a light pulse in the early subjective night $(P<0.01$ for both antigens by independent $t$-test; Fig. 6C, D).

\section{DISCUSSION}

The results of the present study describe for the first time the phase-resetting properties of specific noradrenaline reuptake inhibitors that are used in clinical practice for the management of ADHD and depression. As such it is the first report suggesting that drugs that specifically target the noradrenergic system can phase shift the circadian clock as assessed at the behavioural level. Somewhat surprisingly we report that treatment with atomoxetine in the subjective day against a background of constant light leads to large magnitude phase delays, whereas the same treatment in constant darkness leads to a more modest phase advance. Treatments in either LL or in DD in the night phase did not lead to significant phase alterations. In a similar manner the effects of atomoxetine on c-Fos and CLOCK expression were limited to subjective day treatments, in a similar manner that has been described for other non-photic stimuli (Mikkelsen et al., 1998; Maywood et al., 1999). This phase specificity is typical of non-photic stimuli (Mistlberger and Skene, 2004) and has been described previously for a number of psychoactive substances (Turek and Losee-Olson, 1986; Meijer et al., 2000). However, the large phase delays elicited by atomoxetine (and reboxetine) treatment in LL during the day are not typical following non-photic manipulation in wild-type nocturnal animals, with the smaller magnitude phase advances seen in DD being more typical of non-photic phase shifts. For example, a non-photic manipulation applied in LL that is relatively well studied is the presentation of dark pulses. These 
$\underline{A}$

DD CT6
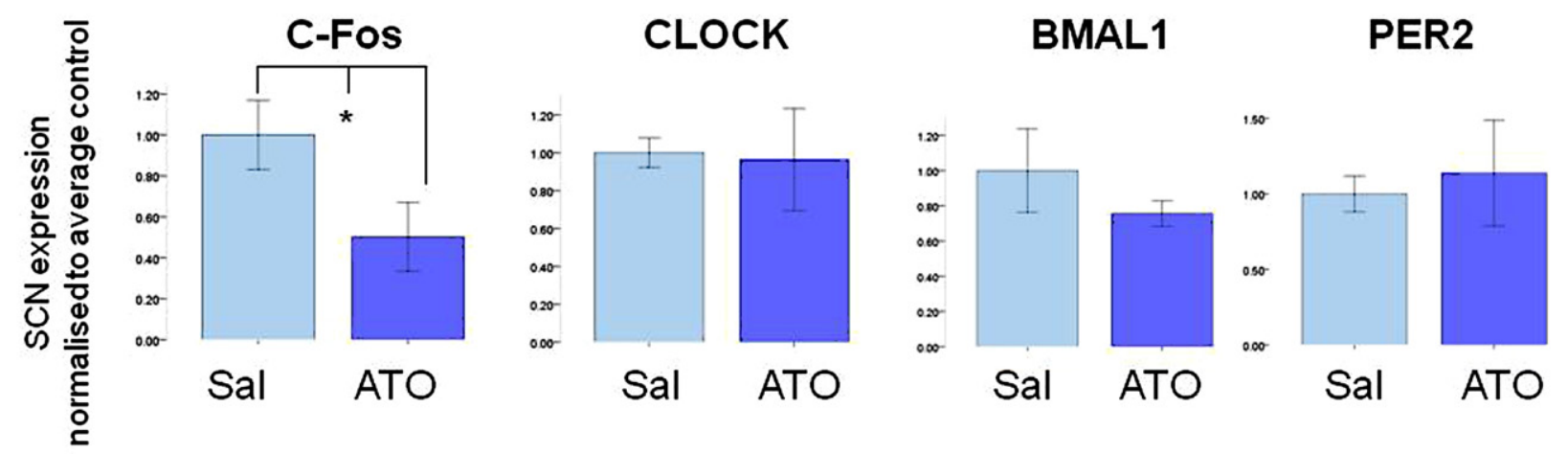

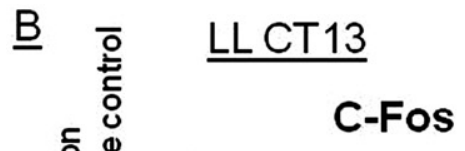

$120-$
$100-$
$0.90-$
$0.00-$
$0.40-$
$0.20-$
$0.00-$
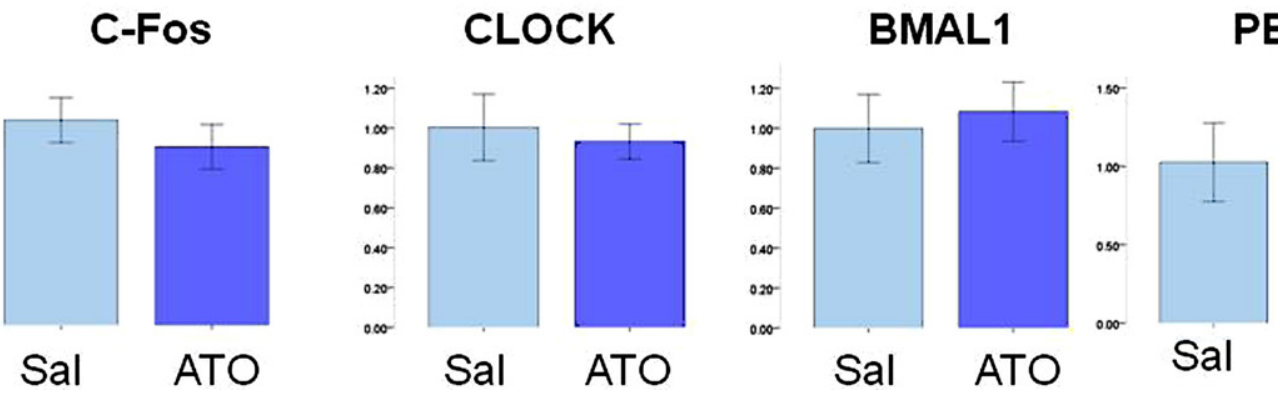

PER2

Fig. 3. Atomoxetine effects on C-Fos, CLOCK, BMAL1 and PER2 in the SCN in the day in DD or during the night in LL. (A) Treatment of animals in DD at CT6 with atomoxetine results in suppression of c-Fos, but not CLOCK, BMAL1 or PER2 in the SCN. ${ }^{*}$ Denotes $P<0.05$. (B) Atomoxetine treatment in LL at CT13 does not induce any significant changes in any of the antigens examined. For interpretation of the references to colour in this figure legend, the reader is referred to the Web version of this article.

produce phase advances of the free-running rhythms when applied during the middle of the subjective day (Boulos and Rusak, 1982) and so can be contrasted with the larger phase delays elicited by atomoxetine in LL in the current study. However given that the mechanisms of phase-resetting by dark pulses may entail a photic as well as non-photic component (e.g. Coogan and Piggins, 2005), such comparisons must be made with caution. There is a report that large magnitude phase delays can be elicited by treatment with an inhibitor of casein-kinase $1 \varepsilon$ in the subjective day (Badura et al., 2007), and so the resetting reported here for atomoxetine in LL is not unprecedented.

\section{Putative mechanisms of atomoxetine actions of circadian rhythms}

The SCN receives sparse noradrenergic innervations (Van den Pol et al., 1985; Cagampang et al., 1994), and the SCN displays both diurnal and circadian rhythms in its NA content, with levels peaking in the middle of the subjective day or the lights on period (Semba et al., 1984; Cagampang et al., 1994), in contrast to rhythms in the rest of the brain (Manshardt and Wurtman, 1968). Noradrenergic fibres appear to regulate expression of the neuropeptides
VIP and AVP (Vacher et al., 2003, 2004), and these peptides are known to be key mediators of SCN circadian function (Welsh et al., 2010). Other studies have shown that monoamine biosynthetic and catabolic pathways are under significant circadian control (Sleipness et al., 2007; Hampp et al., 2008). Within the SCN, there is evidence that there are circadian fluctuations in ligand binding to $\alpha-1$, but not $\alpha-2$ adrenoreceptors (Morien et al., 1999). These findings suggest that the noradrenergic system is under considerable circadian control and matches with our findings of phase-specificity in the action of atomoxetine. The simplest explanation is that atomoxetine exerts its circadian effects directly in the SCN by blocking noradrenaline reuptake during the day phase, when endogenous noradrenaline levels are highest, and is ineffective during the night phase when endogenous levels are lowest, perhaps indicating the reuptake inhibition would have minimal effects at this phase. However, we must presume that atomoxetine (or reboxetine) may exert their effects indirectly through extra-SCN sites, perhaps by modulating other transmitter systems (e.g. acetylcholine, Tzavara et al., 2006) that may impact on circadian timing. Further pharmacological dissection of the circadian effects of atomoxetine and other noradrenergic agents will be required to further examine this issue. 
A

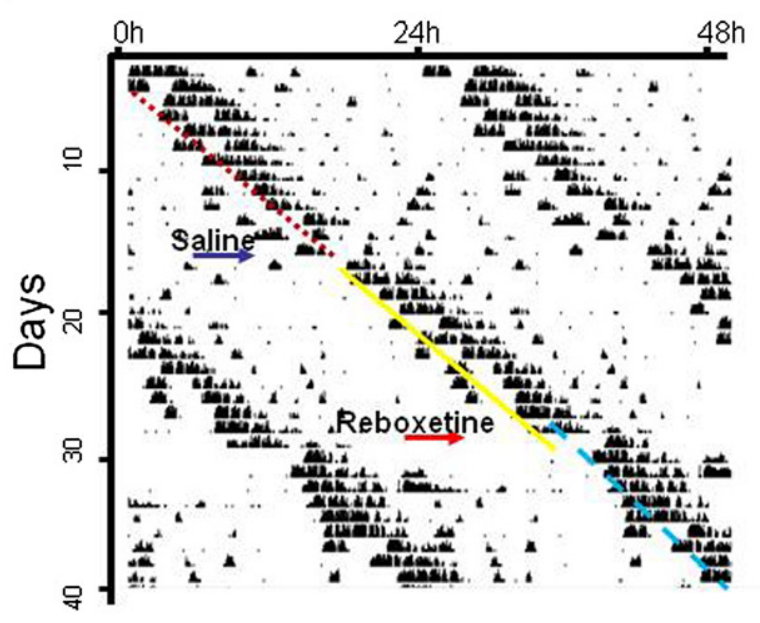

C

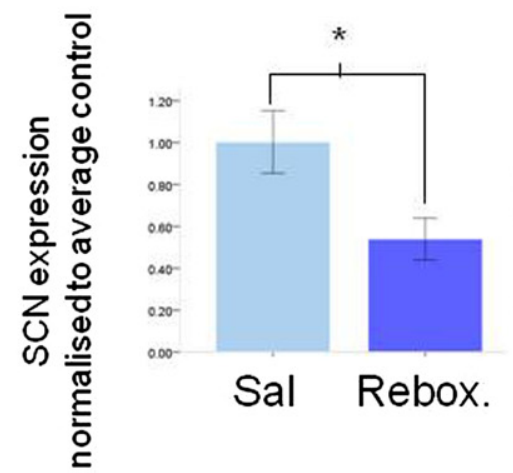

CLOCK

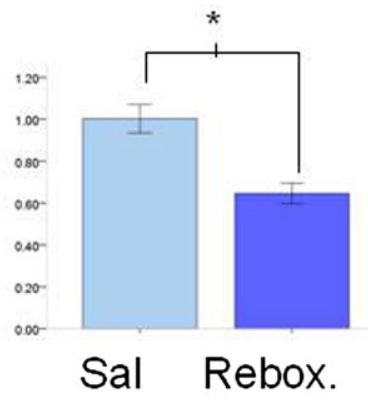

B

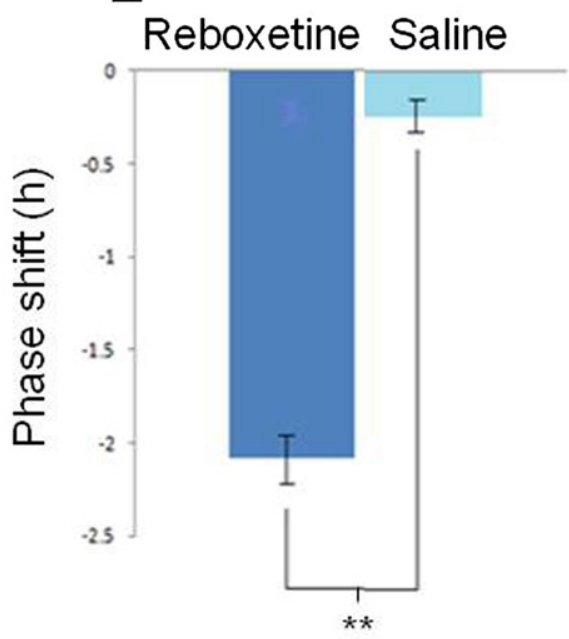

BMAL1

PER2

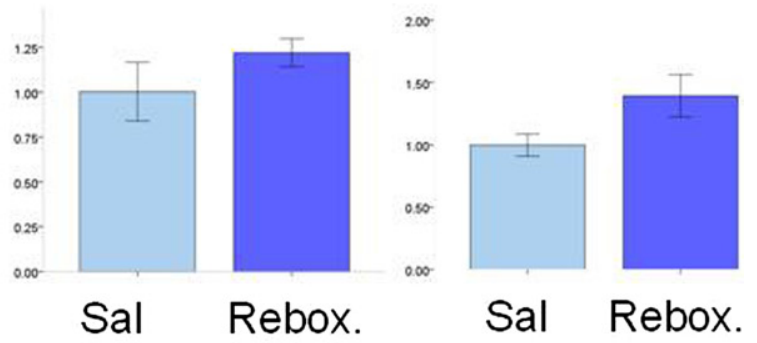

Fig. 4. Reboxetine treatment during the day period in LL induces significant phase delays. (A) Sample double-plotted actogram illustrating that treatment with reboxetine, but not saline, at CT6 in LL produces a phase delay. (B) Mean phase shifts produced by reboxetine and saline in LL at CT6. ** Denotes $P<0.01$. (C) Treatment with reboxetine at CT6 in LL suppresses the SCN expression of C-Fos and CLOCK, but does not alter BMAL1 or PER2 expression. * Denotes $P<0.05$. For interpretation of the references to colour in this figure legend, the reader is referred to the Web version of this article.

A small number of previous studies have examined the effects of manipulating the noradrenergic system pharmacologically on circadian rhythms. Penev et al. $(1993,1994)$ reported that monoamine depletion inhibits wheel running, phase advanced behavioural rhythms in LD, lengthened free-running period and attenuated photically and non-photically induced phase advances. Chronic treatment with the $\alpha-1$ agonist clonidine resulted in a significant shortening of the free-running period of rats, an effect that was reversed upon washout (Rosenwasser, 1989, 1996). Weber et al. (2009) report that treatment with reboxetine at ZT10 inhibits wheel running activity in the early night phase, and this finding is in general agreement with previous studies showing that noradrenaline reuptake inhibitors decrease locomotor behaviour (e.g. Mitchell et al., 2006). Given that atomoxetine is efficacious in producing phase shifts in the current study when treatment occurs during the behaviourally quiescent day phase it seems unlikely that its effects are mediated by suppression of spontaneous wheel-running behaviour.

\section{Clock and immediate early gene regulation by atomoxetine}

Given that in order to effect a change in circadian behaviour at the whole animal level, phase-shifting stimuli must act on the molecular/neuronal mechanisms that underpin circadian timing, we examined the effects of atomoxetine and reboxetine on the expression of clock gene products CLOCK, BMAL1, PER2 and the immediate early gene (IEG) c-Fos. A number of studies have previously examined the effects of adrenergic agents on clock gene expression in a variety of cell and tissue types. Perhaps the best characterized system is the noradrenergic modulation of pineal circadian function, where per1 and cry 1 expression is under noradrenergic regulation through $\beta$-receptors, but not bmal1 or rev-erb-a (Wongchitrat et al., 2009). In cultured spinal astrocytes, per1, but not clock or per2, is 
$\underline{A}$

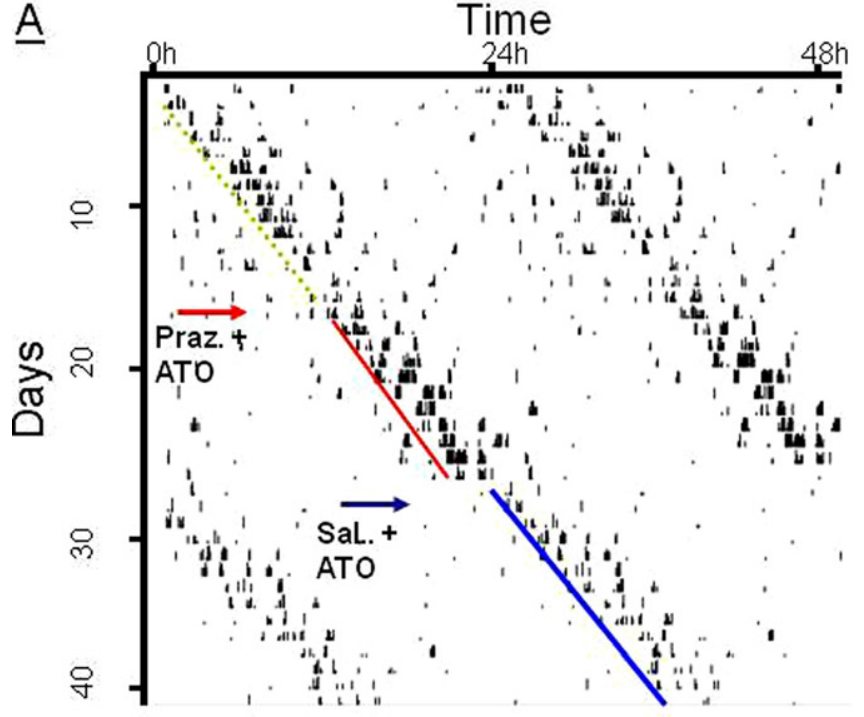

$\underline{\mathrm{C}}$

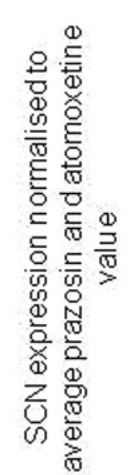

CLOCK

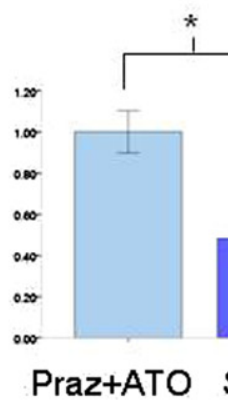

$\underline{B}$

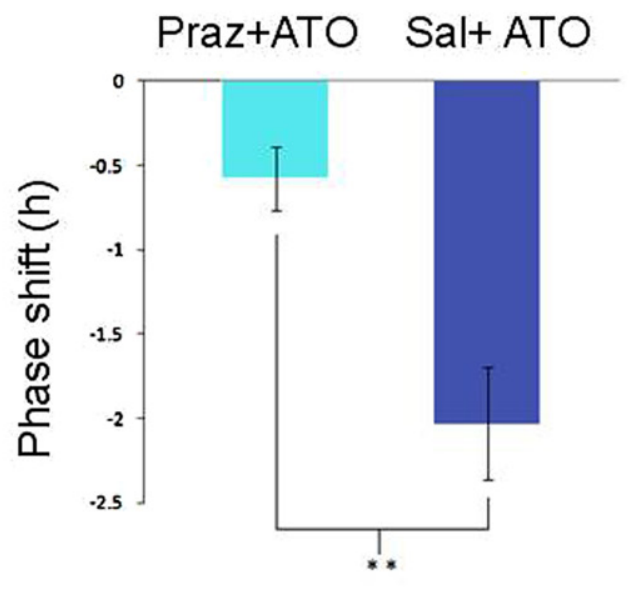

BMAL1

PER2

Fig. 5. Pretreatment with prazosin attenuates the atomoxetine induced effects. (A) Sample double-plotted actogram illustrating that pretreatment with prazosin blocks the atomoxetine-induced phase delay when mice are treated at CT6 in LL. (B) Mean phase shifts produced by atomoxetine treatment when it is preceded by either saline or prazosin. ${ }^{* *}$ Denotes $P<0.01$. (C) Prazosin pretreatment attenuates the atomoxetine-induced suppression of c-Fos and CLOCK in the SCN. * Denotes $P<0.05$. For interpretation of the references to colour in this figure legend, the reader is referred to the Web version of this article.

upregulated by noradrenaline in an $\alpha-1$ and $\beta$-2 receptor dependent manner, whereas bmal1 was regulated in a per1 dependent manner (Sugimoto et al., 2011). In C6 glioma cells regulation of per1 by noradrenaline is $\beta$ receptor dependent (Morioka et al., 2010). Akiyama et al. (2003) report that noradrenaline upregulates per1 and per2 in fibroblasts and liver in an $\alpha-1$ receptor dependent manner. Clonidine (an $\alpha-1$ agonist) treatment was reported not to alter PER2 expression in the SCN, but did so at the start of the light phase in the central amygdala and the bed nucleus of the stria terminalis (Hood et al., 2011). The involvement of $\alpha-1$ receptors in these findings is congruent with our present findings that the effects of atomoxetine were significantly attenuated by the $\alpha-1$ specific antagonist prazosin.

With regards to the changes in c-Fos and CLOCK expression in the SCN elicited by atomoxetine and reboxetine, numerous previous studies have indicated that a wide variety of non-photic stimuli that elicit behavioural phase shifts also suppress SCN levels of c-Fos (e.g. Mik- kelsen et al., 1998; Maywood et al., 1999; Antle and Mistlberger, 2000; Coogan and Piggins, 2005), so the suppression of c-Fos observed in this study fits in with the general picture associated with non-photic phase shifting. As far as we know there are no published examples of CLOCK expression following non-photic stimulation in the $\mathrm{SCN}$, although in other paradigms calorie restriction, interferon- $\alpha$ and age are all found to downregulate CLOCK expression (Wyse and Coogan, 2010; Mendoza et al., 2007; Koyanagi and Ohdo, 2002). It is plausible that the suppression of CLOCK we see is because of post-translational processed regulating protein stability, rather than transcriptionally mediated effects (Mehra et al., 2009). According to the accepted model of the clock gene cycle (Dibner et al., 2010), alteration in the availability CLOCK to form CLOCK/BMAL-1 heterodimers and drive transcription of per/cry genes could lead to an alteration of the phase of the molecular clock that could be translated into a phase shift at the whole animal level. It should be noted here that in the current study we have used immunohistochemistry 

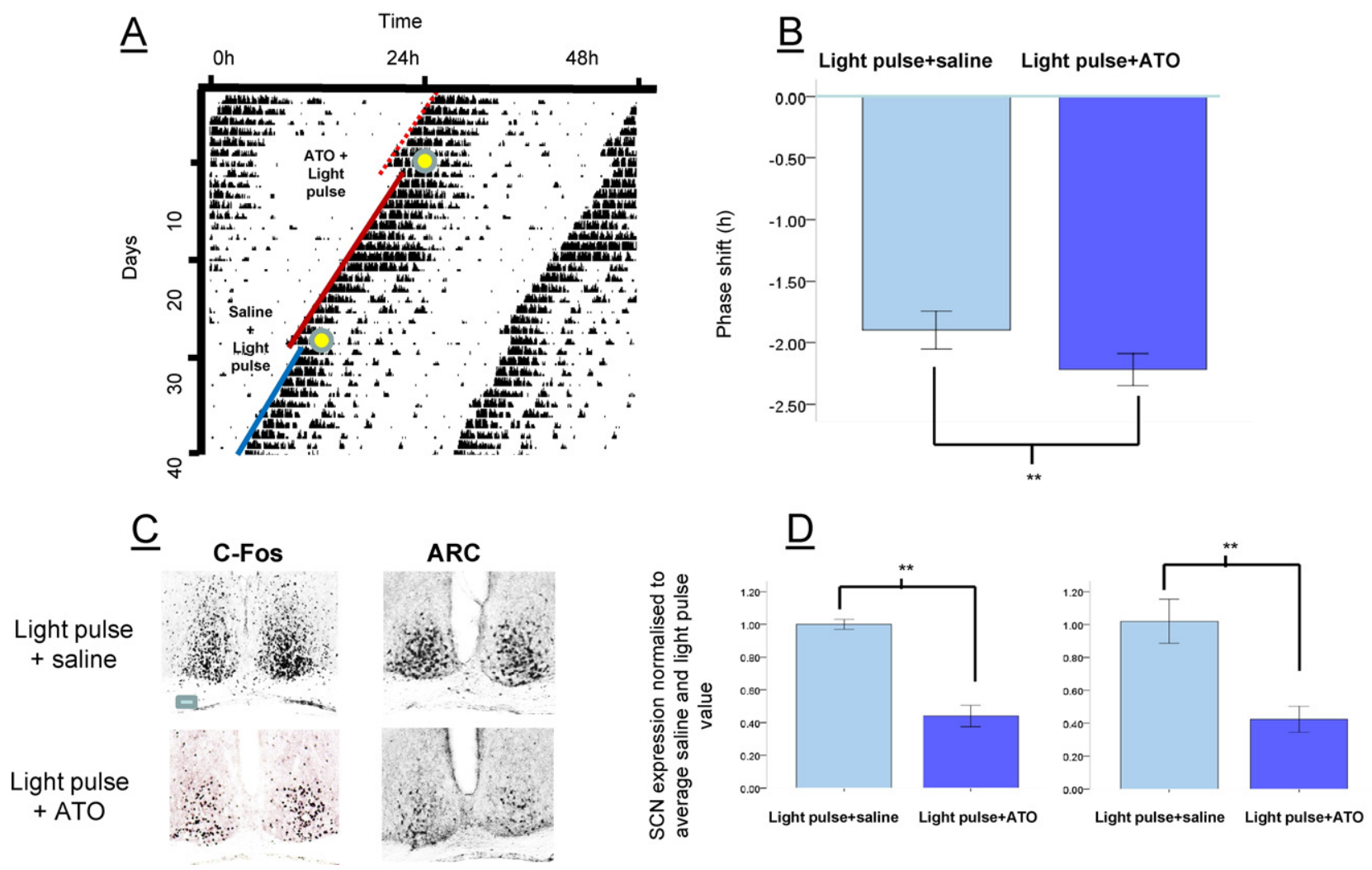

Fig. 6. Effects of atomoxetine on photically induced phase delays and photically induced c-Fos and ARC in the SCN. (A) Sample actogram of a mouse freer-running in DD who receives a 30 min light pulse at CT15 in conjunction with either saline or atomoxetine treatment at CT14.5. (B) Mean phase-delays achieved by a light pulse at CT15 coupled with either saline or atomoxetine pretreatments. ${ }^{* *}$ Denotes $P<0.01$. (C) Sample photomicrographs illustrating SCN expression of c-Fos and ARC in the SCN $1 \mathrm{~h}$ after a light pulse at CT15 in animals pretreated with either saline or atomoxetine. Scale bar $=100 \mu \mathrm{m}$. (D) Mean expression levels of c-Fos and ARC in the SCN following a CT15 light pulse preceded by either saline or atomoxetine. ${ }^{* *}$ Denotes $P<0.01$. For interpretation of the references to colour in this figure legend, the reader is referred to the Web version of this article.

to assess clock gene product expression, rather that assessing mRNA. Given the relatively long lag time between clock gene mRNA expression and clock gene protein product synthesis (e.g. Field et al., 2000) it is possible that the $2 \mathrm{~h}$ after treatment timepoint we sampled at does not allow sufficient time for PER2, BMAL1 or CLOCK upregulation. Given that non-photic stimuli elicit marked downregulation of per2 mRNA (dark pulses, Mendoza et al., 2007; forced activity, Maywood et al., 1999), it is interesting to compare the current results showing no modulation of PER2 by atomoxetine. In future studies it will be of interest to examine the effect of atomoxetine on PER1 expression in the $\mathrm{SCN}$ as well as regulation of other clock components such as CRY $1 / 2$ and REV-REB- $\alpha$.

\section{Differential effects of atomoxetine in LL vs. DD}

We choose to examine the effects of atomoxetine in LL as well as DD because of the fact that a number of previous studies have indicated that circadian responses to pharmacological manipulations of monoaminergic systems is potentiated by exposure to LL. For example, prior LL exposure markedly increased the phase-resetting actions of the serotoninergic agonist 8-OH-DPAT in the hamster (2 days LL exposure plus 8-OH-DPAT resulting in phase shifts as large as $12 \mathrm{~h}$ ), although this potentiating effect of LL attenuated after 3 weeks exposure to LL (Knoch et al., 2004). This LL-induced enhancement of non-photic phase shifting was also seen for phase resetting induced by sleep deprivation and neuropeptide- $Y$ treatment as well as for re-entrainment to shifted light:dark schedules, and is ascribed to $L L$ abolishing the rhythmic release of serotonin in the SCN, although 8-OH-DPAT-induced clock gene expression is not altered (Knoch et al., 2004; Duncan et al., 2005; Kaur et al., 2009). Altered serotoninergic tone in the $\mathrm{SCN}$ in $\mathrm{LL}$ is one possible explanation for the differences in direction and magnitude of phase shift produced by atomoxetine in LL and DD. There are also other possible explanations for these differences.

LL is known to induce weakening of the SCN circadian oscillations and behavioural rhythms, increased circadian period, suppressed activity and can induce behavioural arrhythmicity or splitting (Chen et al., 2008). The limit cycle theoretical model of the SCN pacemaker indicates that manipulations that induce circadian modifications of modest magnitude (as produced here by atomoxetine in DD) may result in much larger phase shifts if the circadian amplitude is weakened sufficiently (Jewett et al., 1991). However a recent study by vanderLeest et al. (2009) has 
shown that in mice maintained in short days with large amplitude circadian rhythms in behaviour, photic stimulation actually induces larger amplitude phase shifts, compared with animals in long days with lower amplitude rhythms. Therefore it may be the case that LL-induced weakening of the circadian amplitude may not be related to the magnitude and direction of the atomoxetine-induced phase shifts reported here. Genetic alterations that result in alteration of the period of the circadian cycle also influence the magnitude of non-photic phase shifts (Mrosovsky et al., 1992) or the direction of these shifts (Challet et al., 2000). Therefore it is possible that the lengthening effect of LL on the behavioural rhythm contributes to the differences observed in the atomoxetine-induced effects in LL compared with DD. Interestingly Rosenwasser (1989, 1996) noted that the effects of the noradrenergic agonist clonidine on shortening free-running circadian period in rats was dependent on photic background through effects on the baseline circadian period.

Another, perhaps interconnected possibility is that LL induces changes in SCN clock gene product expression, resulting in either ablated rhythmicity in PER2 (Muñoz et al., 2005; Chen et al., 2008) or significant phase delays of PER2 (Sudo et al., 2003). LL also alters the SCN expression of c-Fos, PER1 and activated ERK (Sumová and Illnervoá, 2005; Coogan and Piggins, 2005). Thus the effects of photic background on atomoxetine-induced effects may be mediated through LL-induced alterations in clock gene expression. Of interest here is the finding that heterozygous Clock-l+ mice, exposure to novel wheels induces a phase delay, although the same manipulation in wild-type mice results in a phase advance (Challet et al., 2000). Given the effects of atomoxetine treatment in LL (delays) vs. DD (advances), and the suppression of CLOCK by treatments in LL but not DD, there may be a differential role played by CLOCK in determining the type of phase shift that is obtained.

\section{Modulation of photic phase shifting and c-Fos and ARC induction by atomoxetine}

Aside from the effects that atomoxetine exerts on phaseshifting free running rhythms described in this study, we also demonstrate that atomoxetine can alter the effects of light on circadian rhythms and SCN IEG expression by light. We show that atomoxetine pretreatment enhances the magnitude of the phase delay elicited by a light pulse in the early subjective night while also downregulating the photic-induction of c-Fos and ARC. The only other study to examine noradrenergic modulation of photic phase-shifting is by Gannon and Millan (2007) who examined the effects of reboxetine on light-induced phase advances in hamsters and found no significant effect. There are a couple of possible reasons for the apparent discrepancy between atomoxetine's enhancement of photically induced phase delays in the current study and the effects of reboxetine in hamsters. These include differences in pharmokinetics between atomoxetine and reboxetine (Bymaster et al., 2002), species differences between mouse and hamster and dif- ferent effects in the delay versus the advance portions of the photic phase-response curves.

Both c-Fos and ARC are known to be upregulated in the SCN in response to photic stimulation in a phasedependent manner (Kornhauser et al., 1990; Nishimura et al., 2003). These antigens represent two classes of IEGs, c-Fos being a regulatory transcription factor and ARC being a biological effector protein associated with synaptic plasticity (Link et al., 1995), and thus their involvement in the cellular processes underpinning photic resetting may differ. The regulation of both c-Fos and ARC photic induction by atomoxetine would indicate a common component on their photic induction pathway in SCN cells that is amenable to noradrenergic modulation. Various pharmacological manipulations have been found to enhance photic phase-shifting effects, as we describe here, and these enhancements in the behavioural response are not always mirrored by enhanced photic-induction of SCN C-Fos (Smith et al., 2010; Benloucif et al., 2003; Kawaguchi et al., 2003), findings that may be taken as consistent with the current findings of atomoxetine enhancing the magnitude of photically induced phase delays but attenuating light induced c-Fos and ARC expression in the SCN. Of particular interest is the report by Smith et al. (2010) that NAN190 , a 5-HT mixed agonist/antagonist that also has significant affinity for $\alpha-1$ adrenoreceptors, potentiates photically induced phase shifts while suppressing SCN c-Fos induction by light.

\section{CONCLUSION}

The findings that atomoxetine can alter circadian rhythmicity is of possible clinical importance in considering the mechanisms of its therapeutic effects in ADHD. Circadian abnormalities, including phase-delays of the melatonin rhythms and delayed sleep-onset insomnia have been described in ADHD, as well as association with clock gene polymorphisms (Van Veen et al., 2010; Van der Heijden et al., 2005; Kissling et al., 2008). Given that atomoxetine clearly has the potential to alter circadian phase, as well as potential to alter entrainment to zeitgebers, it will be of great interest for future studies to assess these issues in patient populations. This may have far reaching implications for our understanding of the pathophysiology as well as development of possible treatment strategies of neuropsychiatric disorders.

Acknowledgments-We acknowledge financial support from NARSAD. J.T. is supported by pharmaceutical companies (AstraZeneca, Bristol-Myers Squibb, Janssen, Lundbeck, MEDICE, Merz, Novartis, Pfizer, Servier) including some manufacturers of ADHD medication. S.M.O'K. and A.N.C. have no disclosures.

\section{REFERENCES}

Akiyama M, Minami Y, Kuriyama K, Shibata S (2003) MAP kinasedependent induction of clock gene expression by alpha 1-adrenergic receptor activation. FEBS Lett 542:109-114.

Antle MC, Mistlberger RE (2000) Circadian clock resetting by sleep deprivation without exercise in the Syrian hamster. J Neurosci 20:9326-9332. 
Aston-Jones G, Chen S, Zhu Y, Oshinsky ML (2001) A neural circuit for circadian regulation of arousal. Nat Neurosci 4:732-738.

Badura L, Swanson T, Adamowicz W, Adams J, Cianfrogna J, Fisher K, Holland J, Kleiman R, Nelson F, Reynolds L, St. Germain K, Schaeffer E, Tate B, Sprouse J (2007) An inhibitor of casein kinase 1epsilon induces phase delays in circadian rhythms under freerunning and entrained conditions. J Pharmacol Exp Ther 322:730-738.

Benloucif S, Masana MI, Zee PC, Dubocovich ML (2003) Nimodipine potentiates light-induced phase shifts of circadian activity rhythms but not c-fos expression in the suprachiasmatic nucleus of mice. Brain Res 966:157-161.

Beynon AL, Thome J, Coogan AN (2009) Age and time of day influences on the expression of transforming growth factor-beta and phosphorylated SMAD3 in the mouse suprachiasmatic and paraventricular nuclei. Neuroimmunomodulation 16:392-399.

Borgs L, Beukelaers P, Vandenbosch R, Nguyen L, Moonen G, Maquet P, Albrecht U, Belachew S, Malgrange B (2009) Period 2 regulates neural stem/progenitor cell proliferation in the adult hippocampus. BMC Neurosci 10:30.

Boulos Z, Rusak B (1982) Circadian phase response curves for dark pulses in the hamster. J Camp Physiol 146:411-412.

Bymaster FP, Katner JS, Nelson DL, Hemrick-Luecke SK, Threlkeld PG, Heiligenstein JH, Morin SM, Gehlert DR, Perry KW (2002) Atomoxetine increases extracellular levels of norepinephrine and dopamine in prefrontal cortex of rat: a potential mechanism for efficacy in attention deficit/hyperactivity disorder. Neuropsychopharmacology 27:699-711.

Cagampang FR, Okamura H, Inouye S (1994) Circadian rhythms of norepinephrine in the rat suprachiasmatic nucleus. Neurosci Lett 173:185-188.

Challet E, Takahashi JS, Turek FW (2000) Nonphotic phase-shifting in clock mutant mice. Brain Res 859:398-403.

Chen R, Seo DO, Bell E, von Gall C, Lee C (2008) Strong resetting of the mammalian clock by constant light followed by constant darkness. J Neurosci 28:11839-11847.

Coogan AN, Piggins HD (2005) Dark pulse suppression of P-ERK and $\mathrm{c}$-Fos in the hamster suprachiasmatic nuclei. Eur $\mathrm{J}$ Neurosci 22:158-168.

Coogan AN, Thome J (2011) Chronotherapeutics and psychiatry: setting the clock to relieve the symptoms. World J Biol Psychiatry 12 (Suppl 1):40-43.

Cryan JF, O'Leary OF, Jin SH, Friedland JC, Ouyang M, Hirsch BR, Page ME, Dalvi A, Thomas SA, Lucki I (2004) Norepinephrinedeficient mice lack responses to antidepressant drugs, including selective serotonin reuptake inhibitors. Proc Natl Acad Sci U S A 101:8186-8191.

Dibner C, Schibler U, Albrecht U (2010) The mammalian circadian timing system: organization and coordination of central and peripheral clocks. Annu Rev Physiol 17:517-549.

Duncan MJ, Franklin KM, Davis VA, Grossman GH, Knoch ME, Glass JD (2005) Short-term constant light potentiation of large-magnitude circadian phase shifts induced by 8-OH-DPAT: effects on serotonin receptors and gene expression in the hamster suprachiasmatic nucleus. Eur J Neurosci 22:2306-2314.

Field MD, Maywood ES, O'Brien JA, Weaver DR, Reppert SM, Hastings MH (2000) Analysis of clock proteins in mouse SCN demonstrates phylogenetic divergence of the circadian clockwork and resetting mechanisms. Neuron 25:437-447.

Gannon RL, Millan MJ (2007) Evaluation of serotonin, noradrenaline and dopamine reuptake inhibitors on light-induced phase advances in hamster circadian activity rhythms. Psychopharmacology 195:325-332.

Hampp G, Ripperger JA, Houben T, Schmutz I, Blex C, PerreauLenz S, Brunk I, Spanagel R, Ahnert-Hilger G, Meijer JH, Albrecht U (2008) Regulation of monoamine oxidase A by circadian-clock components implies clock influence on mood. Curr Biol 18:678-688.
Hogenesch JB, Panda S, Kay S, Takahashi JS (2003) Circadian transcriptional output in the SCN and liver of the mouse. Novartis Found Symp 253:171-180.

Hood S, Cassidy P, Mathewson S, Stewart J, Amir S (2011) Daily morphine injection and withdrawal disrupt 24-h wheel running and PERIOD2 expression patterns in the rat limbic forebrain. Neuroscience 186:65-75.

Jacomy H, Bosler O (1995) Catecholaminergic innervation of the suprachiasmatic nucleus in the adult rat: ultrastructural relationships with neurons containing vasoactive intestinal peptide or vasopressin. Cell Tissue Res 280:87-96.

Jewett ME, Kronauer RE, Czeisler CA (1991) Light-induced suppression of endogenous circadian amplitude in humans. Nature 350:59-62.

Kaur G, Thind R, Glass JD (2009) Brief constant light accelerates serotonergic re-entrainment to large shifts of the daily light/dark cycle. Neuroscience 159:1430-1440.

Kawaguchi C, Tanaka K, Isojima Y, Shintani N, Hashimoto H, Baba A, Nagai K (2003) Changes in light-induced phase shift of circadian rhythm in mice lacking PACAP. Biochem Biophys Res Commun 310:169-175.

Kissling C, Retz W, Wiemann S, Coogan AN, Clement RM, Hünnerkopf R, Conner AC, Freitag CM, Rösler M, Thome J (2008) A polymorphism at the 3'-untranslated region of the CLOCK gene is associated with adult attention-deficit hyperactivity disorder. Am J Med Genet B Neuropsychiatr Genet 147:333-338.

Knoch ME, Gobes SM, Pavlovska I, Su C, Mistlberger RE, Glass JD (2004) Short-term exposure to constant light promotes strong circadian phase-resetting responses to nonphotic stimuli in Syrian hamsters. Eur J Neurosci 19:2779-2790.

Kornhauser JM, Nelson DE, Mayo KE, Takahashi JS (1990) Photic and circadian regulation of c-fos gene expression in the hamster suprachiasmatic nucleus. Neuron 5:127-134.

Koyanagi S, Ohdo S (2002) Alteration of intrinsic biological rhythms during interferon treatment and its possible mechanism. Mol Pharmacol 62:1393-1399.

Link W, Konietzko U, Kauselmann G, Krug M, Schwanke B, Frey U, Kuhl D (1995) Somatodendritic expression of an immediate early gene is regulated by synaptic activity. Proc Natl Acad Sci U S A 92:5734-5738.

Manshardt J, Wurtman RJ (1968) Daily rhythm in the noradrenaline content of rat hypothalamus. Nature 217:574-575.

Maywood ES, Mrosovsky N, Field MD, Hastings MH (1999) Rapid down-regulation of mammalian period genes during behavioral resetting of the circadian clock. Proc Natl Acad Sci U S A 1996:15211-15216.

Mehra A, Baker CL, Loros JJ, Dunlap JC (2009) Post-translational modifications in circadian rhythms. Trends Biochem Sci 34:483-490.

Meijer JH, Ruijs AC, Albus H, van de Geest B, Duindam H, Zwinderman AH, Dahan A (2000) Fentanyl, a upsilon-opioid receptor agonist, phase shifts the hamster circadian pacemaker. Brain Res 868(1):135-140.

Mendoza J, Pévet $P$, Challet $E$ (2007) Circadian and photic regulation of clock and clock-controlled proteins in the suprachiasmatic nuclei of calorie-restricted mice. Eur J Neurosci 25:3691-3701.

Mikkelsen JD, Vrang N, Mrosovsky N (1998) Expression of Fos in the circadian system following nonphotic stimulation. Brain Res Bull 47:367-376.

Mistlberger RE, Skene DJ (2004) Social influences on mammalian circadian rhythms: animal and human studies. Biol Rev Camb Philos Soc 79:533-556.

Mitchell HA, Ahern TH, Liles LC, Javors MA, Weinshenker D (2006) The effects of norepinephrine transporter inactivation on locomotor activity in mice. Biol Psychiatry 60:1046-1052.

Moga MM, Moore RY (1997) Organization of neural inputs to the suprachiasmatic nucleus in the rat. J Comp Neurol 389:508-534. 
Morioka N, Sugimoto T, Tokuhara M, Dohi T, Nakata Y (2010) Noradrenaline induces clock gene Per 1 mRNA expression in C6 glioma cells through beta(2)-adrenergic receptor coupled with protein kinase A - cAMP response element binding protein (PKA-CREB) and Src-tyrosine kinase - glycogen synthase kinase-3beta (SrcGSK-3beta). J Pharmacol Sci 113:234-245.

Morien A, Cassone VM, Wellman PJ (1999) Diurnal changes in paraventricular hypothalamic alpha1 and alpha2-adrenoceptors and food intake in rats. Pharmacol Biochem Behav 63:33-38.

Morin LP, Allen CN (2006) The circadian visual system, 2005. Brain Res Rev 51:1-60.

Mrosovsky N, Salmon PA, Menaker M, Ralph MR (1992) Nonphotic phase shifting in hamster clock mutants. J Biol Rhythms 7:41-49.

Muñoz M, Peirson SN, Hankins MW, Foster RG (2005) Long-term constant light induces constitutive elevated expression of MPER2 protein in the murine SCN: a molecular basis for Aschoff's rule? J Biol Rhythms 20:3-14.

Nishimura M, Yamagata K, Sugiura H, Okamura H (2003) The activityregulated cytoskeleton-associated (Arc) gene is a new light-inducible early gene in the mouse suprachiasmatic nucleus. Neuroscience 116:1141-1145.

Pendergast JS, Friday RC, Yamazaki S (2010) Photic entrainment of period mutant mice is predicted from their phase response curves. J Neurosci 30:12179-12184.

Penev PD, Turek FW, Zee PC (1993) Monoamine depletion alters the entrainment and the response to light of the circadian activity rhythm in hamsters. Brain Res 612:156-164.

Penev PD, Zee PC, Turek FW (1994) Monoamine depletion blocks triazolam-induced phase advances of the circadian clock in hamsters. Brain Res 637:255-261.

Reppert SM, Weaver DR (2002) Coordination of circadian timing in mammals. Nature 418:935-941.

Rosenwasser AM (1989) Effects of chronic clonidine administration and withdrawal on free-running circadian activity rhythms. Pharmacol Biochem Behav 33:291-297.

Rosenwasser AM (1996) Clonidine shortens circadian period in both constant light and constant darkness. Physiol Behav 60:373-379.

Semba J, Toru M, Mataga N (1984) Twenty-four hour rhythms of norepinephrine and serotonin in nucleus suprachiasmaticus, raphe nuclei, and locus coeruleus in the rat. Sleep 7:211-218.

Sleipness EP, Sorg BA, Jansen HT (2007) Diurnal differences in dopamine transporter and tyrosine hydroxylase levels in rat brain: dependence on the suprachiasmatic nucleus. Brain Res 1129:34-42.

Smith VM, Hagel K, Antle MC (2010) Serotonergic potentiation of photic phase shifts: examination of receptor contributions and early biochemical/molecular events. Neuroscience 165:16-27.

Sudo M, Sasahara K, Moriya T, Akiyama M, Hamada T, Shibata S (2003) Constant light housing attenuates circadian rhythms of mPer2 mRNA and mPER2 protein expression in the suprachiasmatic nucleus of mice. Neuroscience 121:493-499.

Sugimoto T, Morioka N, Sato K, Hisaoka K, Nakata Y (2011) Noradrenergic regulation of period1 expression in spinal astrocytes is involved in protein kinase $\mathrm{A}$, C-Jun $\mathrm{N}$-terminal kinase and extracel- lular signal-regulated kinase activation mediated by $\alpha 1$ - and $\beta 2$-adrenoceptors. Neuroscience 185:1-13.

Sumová A, Illnerová H (2005) Effect of photic stimuli disturbing overt circadian rhythms on the dorsomedial and ventrolateral SCN rhythmicity. Brain Res 1048:161-169.

Terazono H, Mutoh T, Yamaguchi S, Kobayashi M, Akiyama M, Udo R, Ohdo S, Okamura H, Shibata S (2003) Adrenergic regulation of clock gene expression in mouse liver. Proc Natl Acad Sci U S A 100:6795-6800.

Turek FW, Losee-Olson S (1986) A benzodiazepine used in the treatment of insomnia phase-shifts the mammalian circadian clock. Nature 321:167-170.

Tzavara ET, Bymaster FP, Overshiner CD, Davis RJ, Perry KW, Wolff M, McKinzie DL, Witkin JM, Nomikos GG (2006) Procholinergic and memory enhancing properties of the selective norepinephrine uptake inhibitor atomoxetine. Mol Psychiatry 11:187-195.

Vacher CM, Calas A, Maltonti F, Hardin-Pouzet H (2004) Postnatal regulation by monoamines of vasopressin expression in the neuroendocrine hypothalamus of MAO-A-deficient mice. Eur J Neurosci 19:1110-1114.

Vacher CM, Frétier P, Créminon C, Seif I, De Maeyer E, Calas A, Hardin-Pouzet H (2003) Monoaminergic control of vasopressin and VIP expression in the mouse suprachiasmatic nucleus. J Neurosci Res 71:791-801.

van den Pol AN, Tsujimoto KL (1985) Neurotransmitters of the hypothalamic suprachiasmatic nucleus: immunocytochemical analysis of 25 neuronal antigens. Neuroscience 15:1049-1086.

Van der Heijden KB, Smits MG, Van Someren EJ, Gunning WB (2005) Idiopathic chronic sleep onset insomnia in attention-deficit/hyperactivity disorder: a circadian rhythm sleep disorder. Chronobiol Int 22:559-570.

vanderLeest HT, Rohling JH, Michel S, Meijer JH (2009) Phase shifting capacity of the circadian pacemaker determined by the SCN neuronal network organization. PLoS One 4:e4976.

Van Veen MM, Kooij JJ, Boonstra AM, Gordijn MC, Van Someren EJ (2010) Delayed circadian rhythm in adults with attention-deficit/ hyperactivity disorder and chronic sleep-onset insomnia. Biol Psychiatry 67:1091-1096.

Weber M, Talmon S, Schulze I, Boeddinghaus C, Gross G, Schoemaker H, Wicke KM (2009) Running wheel activity is sensitive to acute treatment with selective inhibitors for either serotonin or norepinephrine reuptake. Psychopharmacology 203:753-762.

Welsh DK, Takahashi JS, Kay SA (2010) Suprachiasmatic nucleus: cell autonomy and network properties. Annu Rev Physiol 72:551-557.

Wirz-Justice A (2009) From the basic neuroscience of circadian clock function to light therapy for depression: on the emergence of chronotherapeutics. J Affect Disord 116:159-160.

Wongchitrat $\mathrm{P}$, Felder-Schmittbuhl MP, Phansuwan-Pujito P, Pévet $\mathrm{P}$, Simonneaux V (2009) Endogenous rhythmicity of Bmal1 and Reverb alpha in the hamster pineal gland is not driven by norepinephrine. Eur J Neurosci 29:2009-2016.

Wyse CA, Coogan AN (2010) Impact of aging on diurnal expression patterns of CLOCK and BMAL1 in the mouse brain. Brain Res 1337:21-31. 